\title{
Artificial Neural Network Controller Based Distribution Static Compensator for Voltage Sag Mitigation
}

\author{
${ }^{1} D$. Rajasekaran, ${ }^{2}$ Subhransu Sekhar Dash, \\ ${ }^{3}$ Arun Bhaskar Mayilvaganan, ${ }^{2}$ C. Subramani and ${ }^{3}$ Sathyanarayan Krishnan \\ ${ }^{1}$ Department of Electrical and Electronics Engineering, R.M.D. Engineering College, Chennai, Tamil Nadu, India \\ ${ }^{2}$ Department of Electrical and Electronics Engineering, SRM University, Chennai, Tamil Nadu, India \\ ${ }^{3}$ Department of Electrical and Electronics Engineering, Velammal Engineering College, Chennai, Tamil Nadu, India
}

Received 2013-02-18, Revised 2013-06-19; Accepted 2013-06-21

\begin{abstract}
Switching of loads, capacitors, along with the proliferation of power electronics equipment, non-linear loads in industrial, commercial and domestic applications have lead to power quality issues in the distribution system. Power quality issues such as voltage sag, voltage swell and harmonics, which are certainly major concerning issues in the present era. These issues can lead to failure or malfunction of the many sensitive loads connected to the distribution system, thus incurring a high cost for end users. Power quality problems are solved by advanced custom power devices. This study presents how the custom power device Distribution Static Compensator (D-STATCOM) is used to mitigate voltage sag and voltage harmonics in distribution system. Artificial Neural Network (ANN) controller based D-STATCOM is simulated in MATLAB-SIMULINK environment. Prototype model for single phase D-STATCOM is developed to verify the results. The simulation and hardware results show clearly the performance of the D-STATCOM in mitigating voltage sag and voltage harmonics in distribution system.
\end{abstract}

Keywords: Power Quality, D-STATCOM, Voltage Sag, IGBT, MATLAB/SIMULINK, Energy Storage System, Artificial Neural Network

\section{INTRODUCTION}

Voltage sag and voltage harmonics are the most important Power Quality (PQ) problems that many industries and utilities face it. Sensitive equipments used in modern industrial plants such as programmable logic controllers, process controllers and adjustable speed drives are not tolerate voltage sag and voltage harmonics (Dugan et al., 2003; Singh et al., 2009). The DSTATCOM has emerged as a promising device to provide voltage sag mitigation and harmonic control (Hosseini et al., 2011). The single line diagram of DSTATCOM is shown in Fig. 1. The D-STATCOM is connected in shunt to the system (Babaei et al., 2010).
The Voltage Source Converter (VSC) converts the dc voltage into a set of three-phase ac output voltage across the energy storage device. Output voltage from VSC is in phase and connected with the distribution System using the coupling transformer (Hosseini et al., 2011). PWMbased control scheme which requires a current controller for generating the gating signals for IGBTs in VSC by using the reference and sensed source currents (Kannan and Rengarajan, 2012). Fuzzy-PI direct output voltage control strategy is presented to mitigate voltage sag in utility distribution system (Luo et al., 2009a; 2009b). This study will investigate the capability of the ANN controller based D-STATCOM on mitigation of voltage sag and voltage harmonics.

Corresponding Author: Rajasekaran, D., Department of Electrical and Electronics Engineering, R.M.D. Engineering College, Chennai, Tamil Nadu, India 


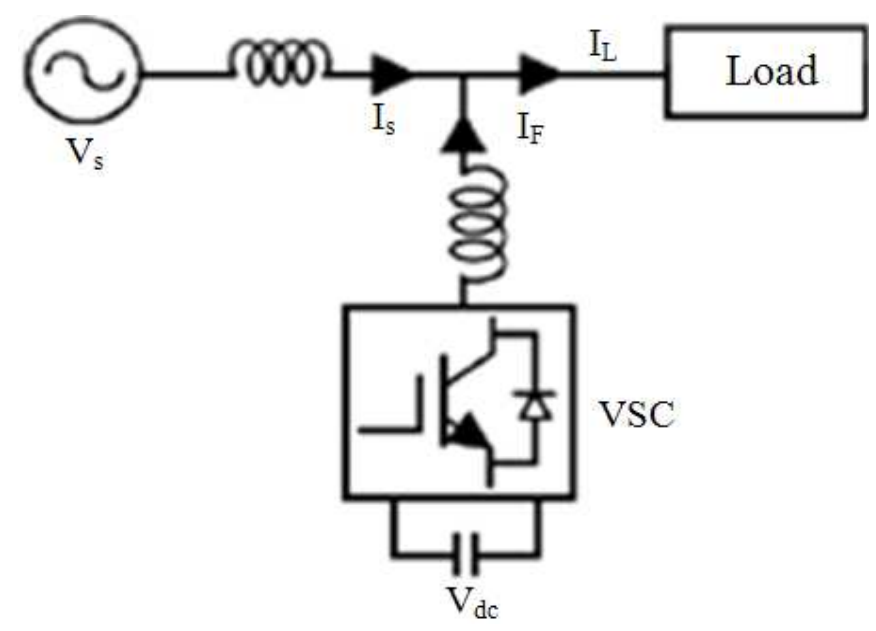

Fig. 1. Single line diagram of D-STATCOM

D-STATCOM is simulated in MATLAB/SIMULINK software. The simulation results show clearly ANN controller based D-STATCOM handled the situation without any difficulties and thereby keeping the load voltage balanced and constant at the nominal value and it also reduces voltage harmonics within the accepted range. Single phase hardware is implemented to verify the simulation results.

\section{MATERIALS AND METHODS}

Figure 2 shows the single line diagram of distribution system under study. ANN controller based D-STATCOM is connected in the distribution system to mitigate voltage sag and voltage harmonics.

\subsection{The ANN Controller}

Figure 3 shows the diagram of Artificial Neural Network (ANN) controller. The ANN controller used in this control system, consists of three neuron layers, the input, the hidden and the output layer. The ANN has three inputs $\left(\mathrm{V}_{\mathrm{a}}, \mathrm{V}_{\mathrm{b}}, \mathrm{V}_{\mathrm{c}}\right)$ and three outputs $\left(\mathrm{V}_{\mathrm{a}}{ }^{*}, \mathrm{~V}_{\mathrm{b}}{ }^{*}\right.$, $\mathrm{V}_{\mathrm{c}}{ }^{*}$ ). The output of ANN passes through a comparator and is compared with a carrier signal before applying as reference variable to the PWM generator. The ANN is trained by varying the weights $\mathrm{W}_{\mathrm{ij}}$ and the biases $\mathrm{B}_{\mathrm{j}}$. The training criterion is taken as the mean square error of the ANN output with a value of 0.0001 and the error function is defined by the following Equation (1):

$$
J=\sum_{i=1}^{N} e(i)^{2}
$$

Table 1. Simulated system parameters

\begin{tabular}{ll}
\hline Main supply voltage phase to phase & $11 \mathrm{kV}$ \\
\hline Line Impedance & $0.2 \Omega, 1 \mathrm{mH}$ \\
Shunt transformer turns ratio & $1: 1$ \\
Filter Inductance & $2 \mathrm{mH}$ \\
Filter capacitance & $1 \mu \mathrm{F}$ \\
Load resistance & $0.001 \Omega$ \\
Load inductance & $0.005 \mathrm{H}$ \\
Load capacitance & $1 \mathrm{e}-6 \mathrm{~F}$ \\
Line Frequency & $50 \mathrm{~Hz}$ \\
\hline
\end{tabular}

where, $\mathrm{N}$ is the number of output neurons and e(i) is the instantaneous error between the actual and estimated values of the output. The training is completed when the value of $\mathrm{j}$ is less than 0.0001 (Mohaghegi et al., 2005).

\section{RESULTS AND DISCUSSION}

\subsection{Simulation Results}

ANN controller based D-STATCOM is modeled and simulated by using MATLAB/Simulink. The learning process of ANN is developed in MATLAB, aided by the neural network toolbox. Simulated system parameters are given in Table $\mathbf{1}$.

At an initial stage non-critical load is connected to the distribution system from 0 to $0.05 \mathrm{sec}$. During this time rated voltage is available across load 1 i.e., no voltage sag. At $0.05 \mathrm{sec}$ critical load is connected to the distribution system, the system voltage drops to $50 \%$ of its nominal value. The voltage sag occurs from 0.05 to $0.15 \mathrm{sec}$ as shown in Fig. 4. To mitigate the voltage sag the required voltage is injected by the ANN controller based DSTATCOM from 0.06 to $0.14 \mathrm{sec}$ as shown in Fig. 5. The Compensated voltage across the load is shown in Fig. 6. 
D. Rajasekaran et al. / American Journal of Applied Sciences 10 (7): 688-695, 2013

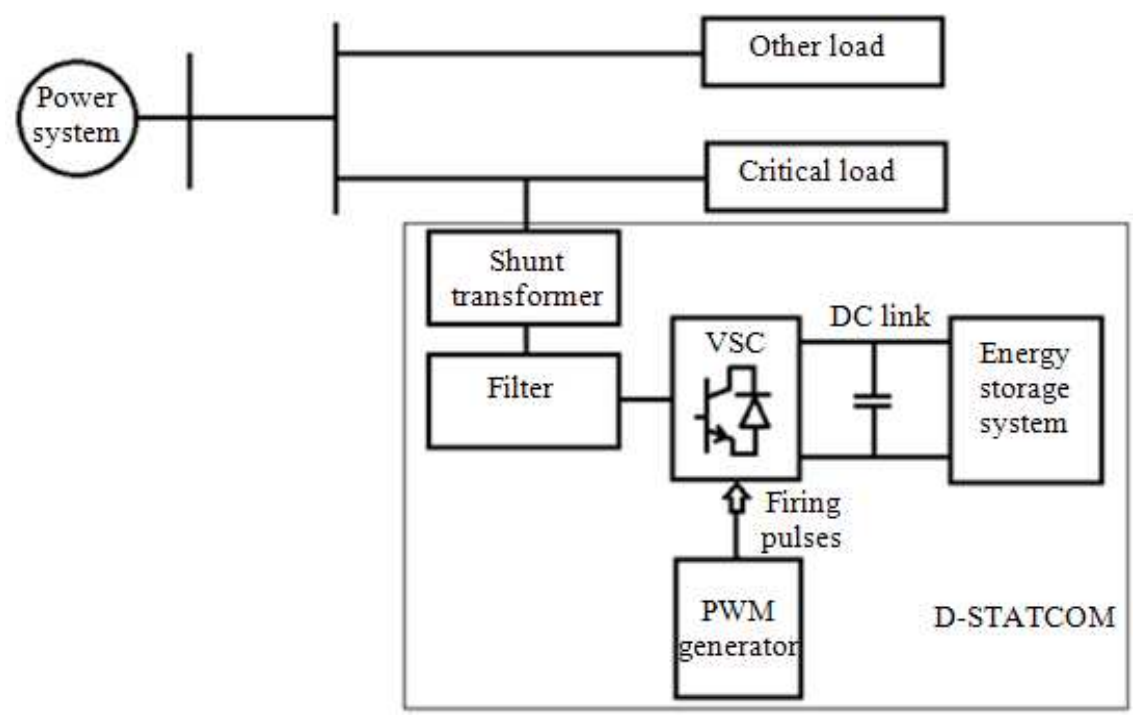

Fig. 2. Single line diagram of distribution system under study with D-STATCOM

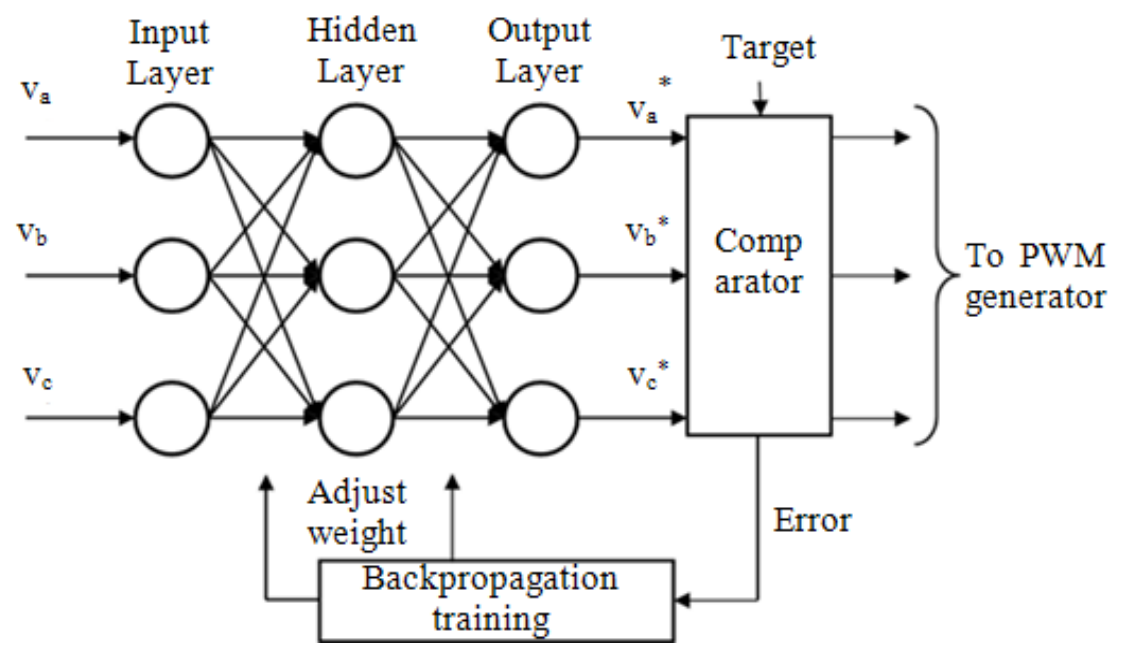

Fig. 3. ANN controller

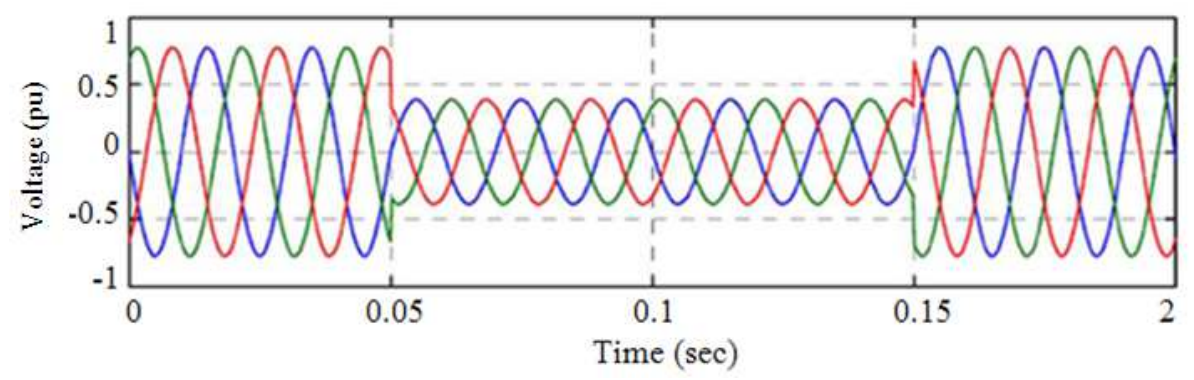

Fig. 4. Voltage under voltage sag condition 
D. Rajasekaran et al. / American Journal of Applied Sciences 10 (7): 688-695, 2013

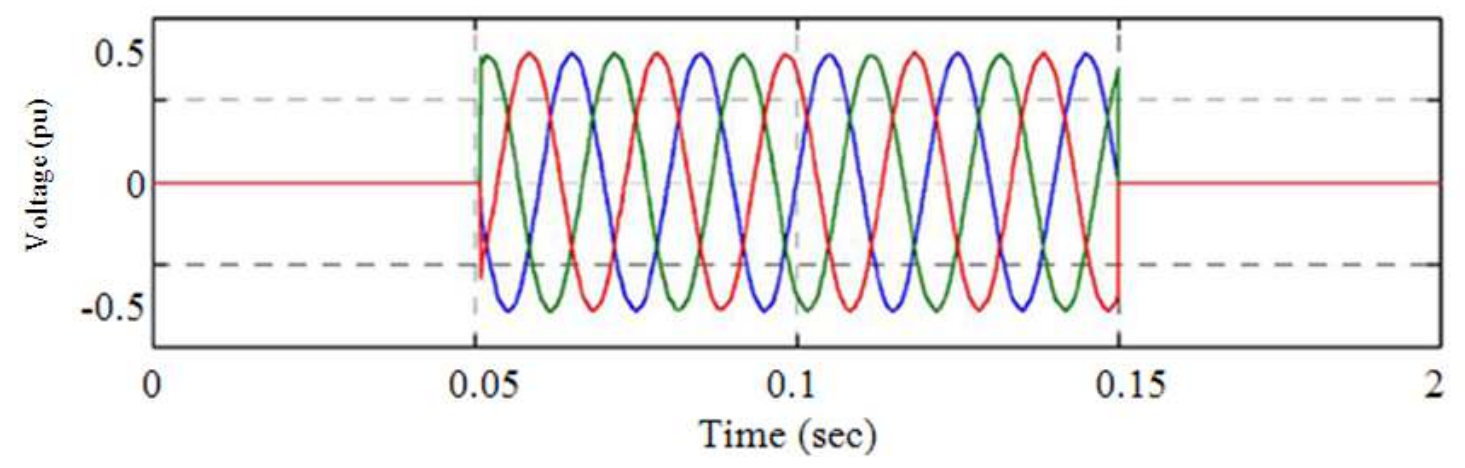

Fig. 5. Voltage Injected by D-STATCOM

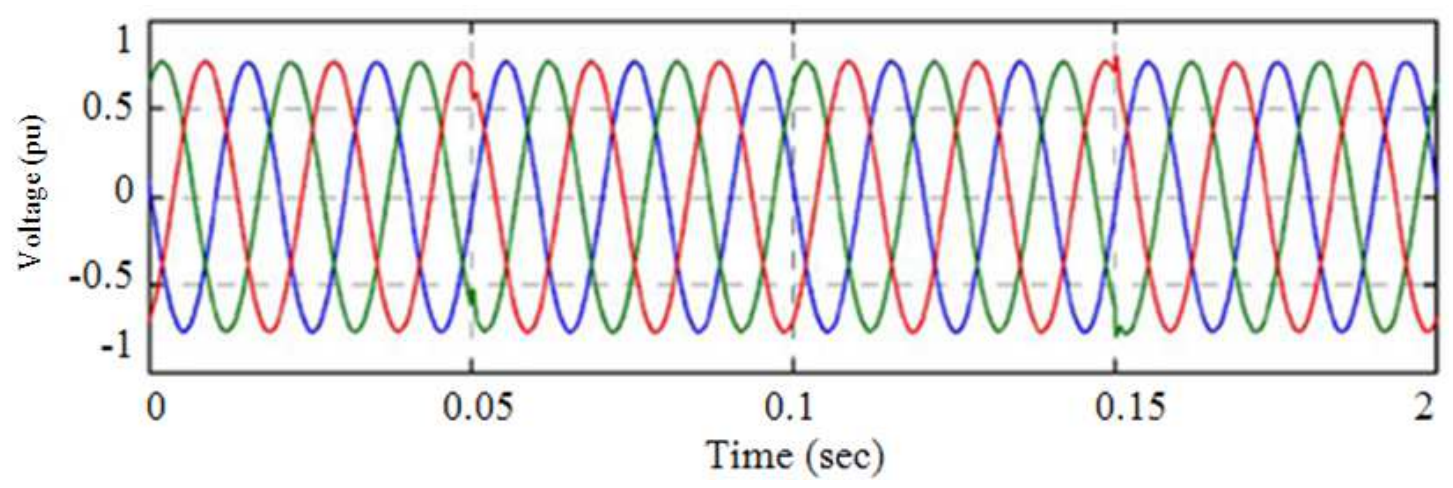

Fig. 6. Load voltage after compensation

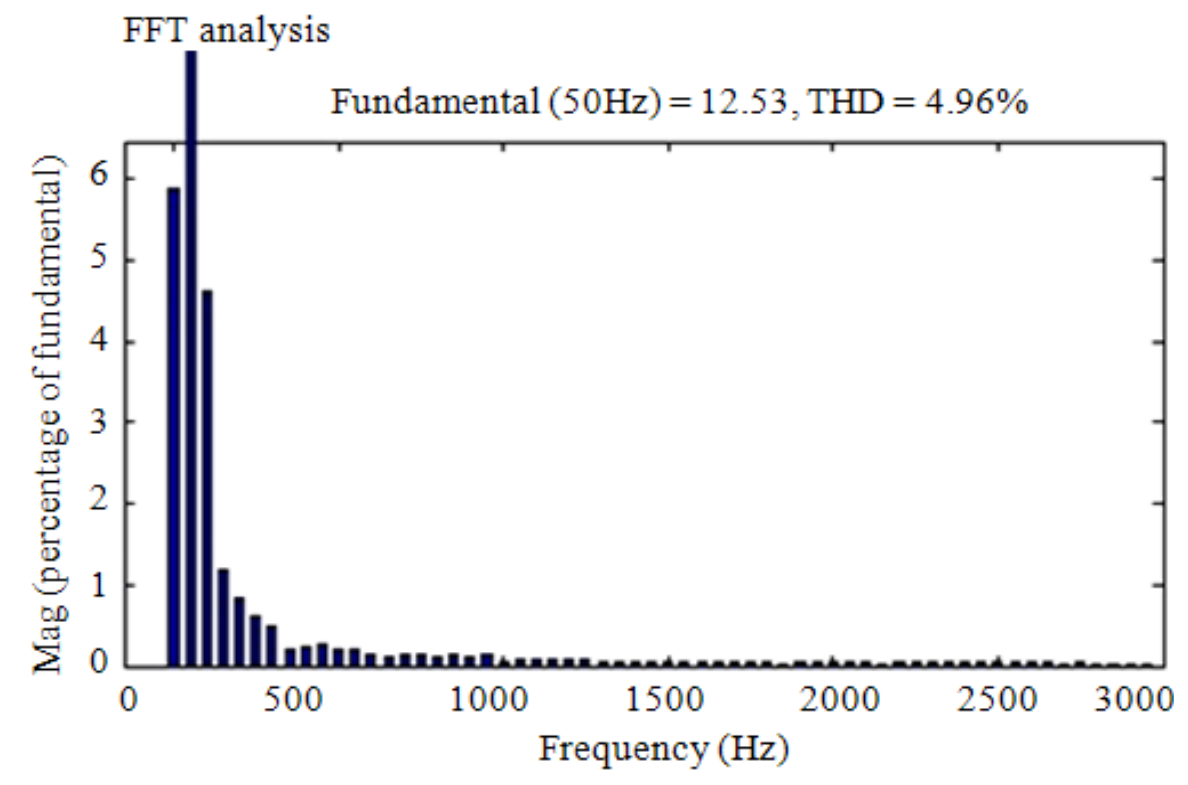

Fig. 7. FFT analysis without D-STATCOM 


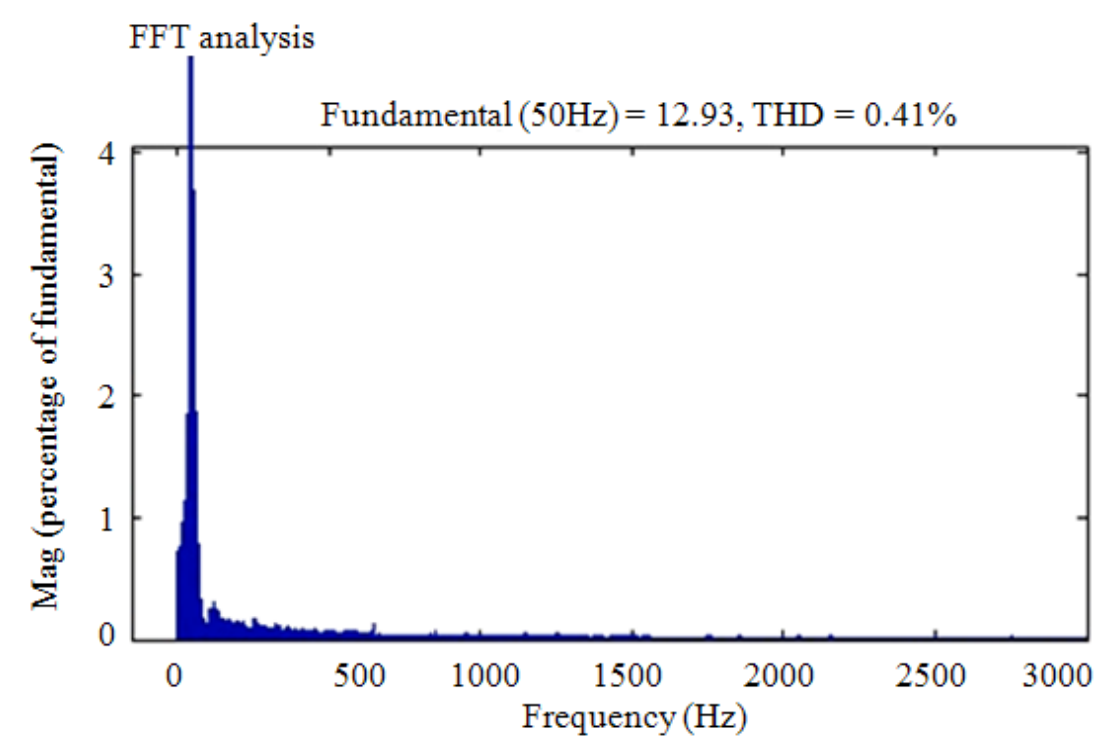

Fig. 8. FFT analysis with D-STATCOM

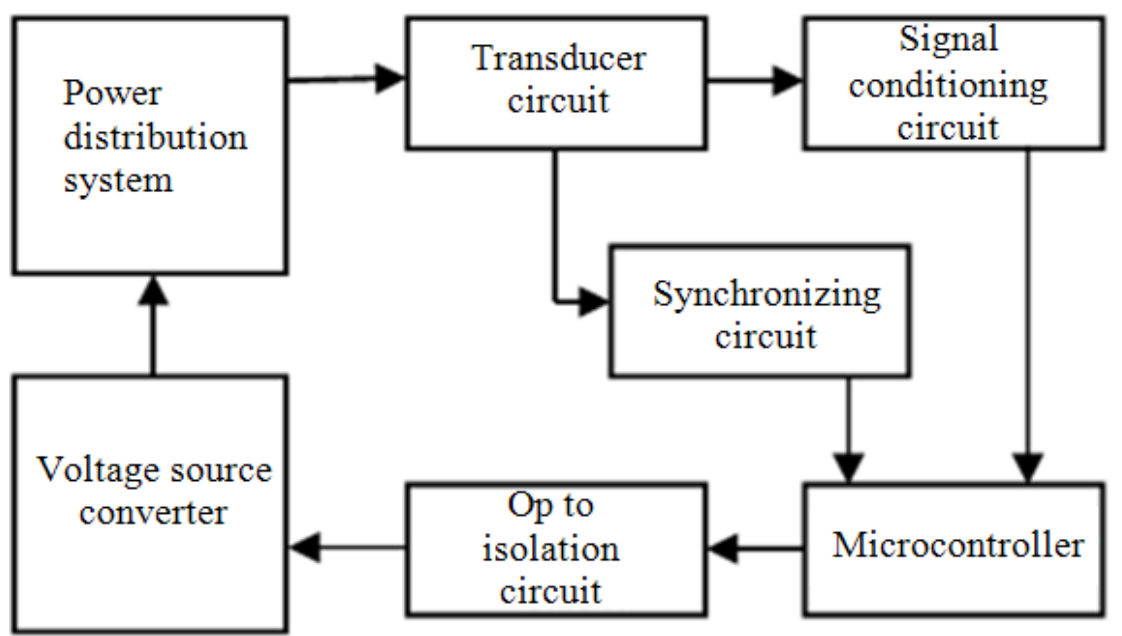

Fig. 9. Block diagram of single phase hardware model for D-STATCOM

The FFT analysis for the output voltage without DSTATCOM and with D-STATCOM is shown in Fig. 7 and 8. Figure 7 gives FFT analysis without D-STATCOM. The THD value for this case is $4.96 \%$. Figure 8 gives FFT analysis with D-STATCOM. The THD value for this case is $0.41 \%$. Thus THD is reduced from 4.96 to $0.41 \%$ by using ANN controller based D-STATCOM.

The simulation results show the effectiveness of DSTATCOM to mitigate voltage sag and voltage harmonics in the distribution system. THD values with and without D-STATCOM are shown in Table 2.
Table 2. THD values without and with D-STATCOM

\begin{tabular}{lll}
\hline THD & Without D-STATCOM & With D-STATCOM \\
\hline $4.96 \%$ & $0.41 \%$ \\
\hline
\end{tabular}

\subsection{Description of Hardware Modules}

Figure 9 shows block diagram of single phase hardware model for D-STATCOM.

The major components of microcontroller based DSTATCOM is given as follows: 
- Transducer circuit

- Signal conditioning circuit

- Synchronizing circuit

- Microcontroller

- Opto isolation circuit

- Voltage source converter

The detailed description of different parts of the hardware is given below.

\subsection{Transducer Circuit}

The power quantities are sensed and converted into low level signal in transducer circuit.

\subsection{Signal Conditioning Circuit}

The low level signal from transducer circuit is converted into $0-5 \mathrm{~V}$ range to make them compatible with microcontroller.

\subsection{Synchronizing Circuit}

The PCC voltages are distorted and not possess sharp zero crossing. So it is difficult to find zero crossing from
PCC voltages. Hence synchronizing circuit is required to extract and synchronize desired signal.

\subsection{Microcontroller}

It is a small computer on a single integrated circuit containing processor, memory and programmable input/output peripherals. From the signal conditioning circuit the signal is given to the microcontroller in which the artificial neural network algorithm takes care of the PWM signal.

\subsection{Opto Isolation Circuit}

Opto couplers are used to provide isolation between control circuit and power circuit.

\subsection{Voltage Source Converter}

Output of the microcontroller is PWM signals. These PWM signals are used as the gate trigger pulses for voltage source converter.

Output from the voltage source converter is applied to the injection transformer which is in parallel with the line to mitigate voltage sag and voltage harmonics.

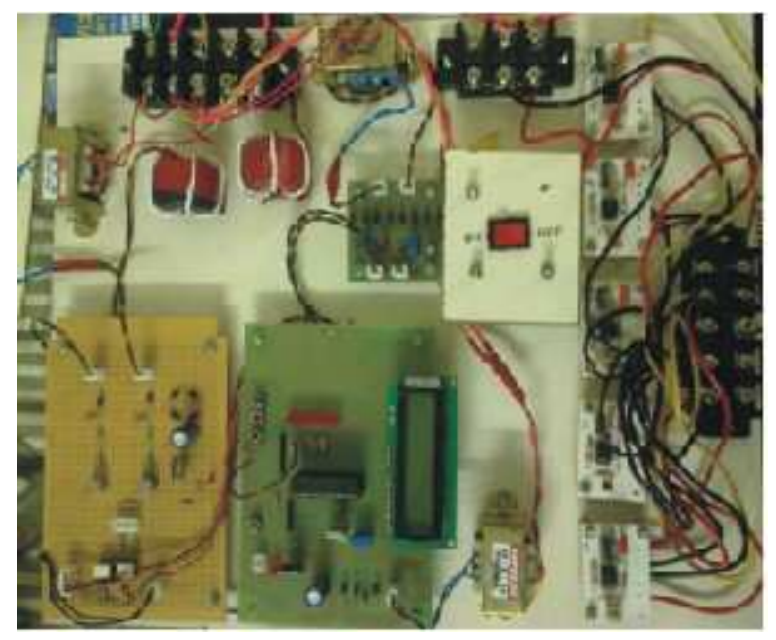

Fig. 10. Single phase hardware model of D-STATCOM

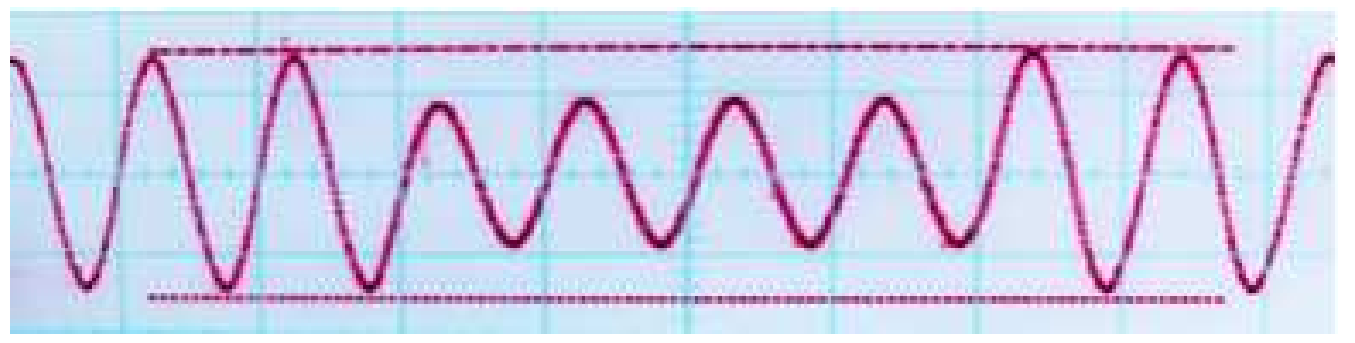

Fig. 11. Voltage under voltage sag condition 


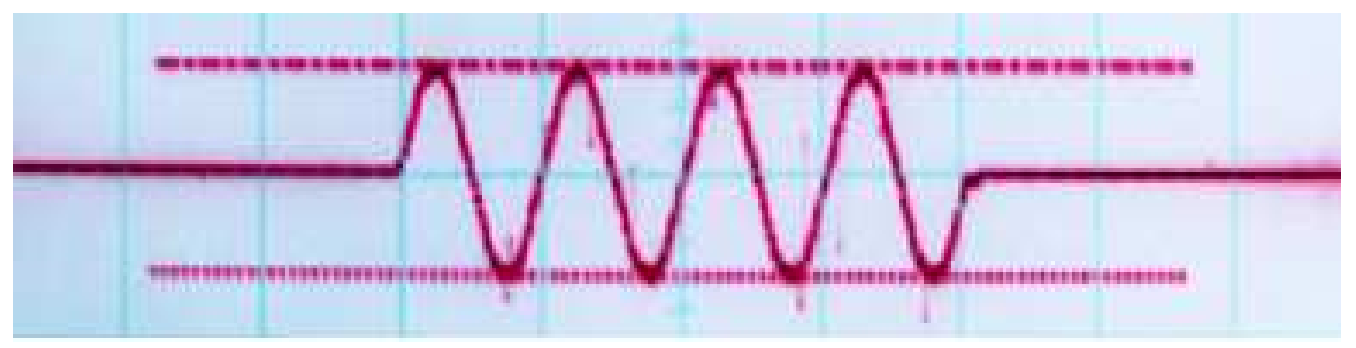

Fig. 12. Voltage injected by D-STATCOM

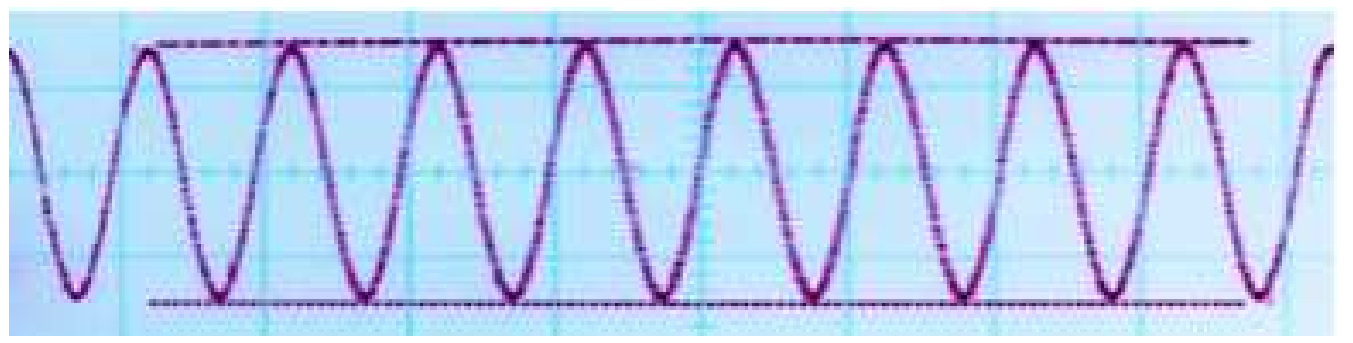

Fig. 13. Load voltage after compensation

\subsection{Experimental Results}

The photograph of the single phase hardware for DSTATCOM to mitigate voltage sag is shown in Fig. 10. The output voltage of the system without D-STATCOM is shown in Fig. 11. From the Fig. 11 it is identified that $50 \%$ sag occurs without D-STATCOM. When sag occurs DSTATCOM inject appropriate voltage i.e., $50 \%$ voltage to power system as shown in Fig. 12. The load voltage after compensation is shown in Fig. 13. It can be seen that the output voltage across the load is nearly nominal value (i.e., 1 p.u.) and sinusoidal.

\section{CONCLUSION}

This study presents how the custom power device D-STATCOM is used to mitigate voltage sag and voltage harmonics in distribution system. ANN controller based D-STATCOM is simulated in MATLAB-SIMULINK environment. Three multilayer neural network is used to identify and regulate the voltage across sensitive load. Microcontroller based hardware for single phase D-STATCOM is developed to verify the results. The simulation and experimental results shows the effectiveness of D-STATCOM to mitigate voltage sag and voltage harmonics in distribution system.

\section{REFERENCES}

Babaei, E., A. Nazarloo and S.H. Hosseini, 2010. Application of flexible control methods for DSTATCOM in mitigating voltage sags and swells. Proceedings of the IEEE International Power and Energy Conference, Oct. 27-29, IEEE Xplore Press, Singapore, pp: 590-595. DOI: 10.1109/IPECON.2010.5697063

Dugan, R.C., M.F. MacGranaghan and H.W. Beaty, 2003. Electrical Power Systems Quality. 2nd Edn., McGraw-Hill, New York, ISBN-10: 007138622X, pp: 528.

Hosseini, S.H., A. Nazarloo and E. Babaei, 2011. SuperCapacitor based D-STATCOM applied in IEEE 13bus industrial distribution system. Proceedings of the 8th International Conference on Electrical Engineering/Electronics, Computer, Telecommunications and Information Technology, May 17-19, IEEE Xplore Press, Khon Kaen, pp: 715-718. DOI: 10.1109/ECTICON.2011.5947940

Kannan, V.K. and N. Rengarajan, 2012. Photovoltaic based distribution static compensator for power quality improvement. Int. J. Elect. Power Energy Syst., 42: 685-692. DOI: 10.1016/j.ijepes.2012.04.061 
Luo, A., C. Tang, Z. Shuai, J. Tang and X.Y. Xu et al., 2009a. Fuzzy-PI-based direct-output-voltage control strategy for the STATCOM used in utility distribution systems. IEEE Trans. Indus. Elect., 56: 2401-2411. DOI: 10.1109/TIE.2009.2021172

Luo, A., C. Tang, Z. Shuai, J. Tang and X.Y. Xu et al., 2009b. Fuzzy-PI-based direct-output-voltage control strategy for the STATCOM used in utility distribution systems. IEEE Trans. Indus. Elect., 56: 2401-2411. DOI: 10.1109/TIE.2009.2021172
Mohaghegi, S., Y.D. Valle, G.K. Venayagamoorthy and R.G. Harley, 2005. A comparison of PSO and backpropagation for training RBF neural networks for identification of a power system with STATCOM. Proceedings of the IEEE Swarm Intelligence Symposium, Swarm Intelligence Symposium, Jun. 8-10, IEEE Xplore Press, pp: 381384. DOI: $10.1109 /$ SIS.2005.1501646

Singh, G.K., 2009. Power system harmonics research: A survey. Eur. Trans. Elect. Power, 19: 151-172. DOI: $10.1002 /$ etep.201 